\title{
Ciprofloxacin or imipenem use correlates with resistance in Pseudomonas aeruginosa
}

\author{
George G Zhanel PharmD PhD ${ }^{1,2}$, Lindsay E Nicolle MD FRCPC ${ }^{1,2}$, Alfred S Gin PharmD ${ }^{2}$, \\ James Karlowsky $\mathrm{PhD}^{1}$, Amin Kabani $\mathrm{MD}^{1,2}$, Daryl J Hoban $\mathrm{PhD}^{1,2}$
}

\begin{abstract}
GG Zhanel, LE Nicolle, AS Gin, J Karlowsky, A Kabani, DJ Hoban. Ciprofloxacin or imipenem use correlates with resistance in Pseudomonas aeruginosa. Can J Infect Dis 1998;9(6):382-386.

OBJECTIVE: To investigate the relationship between ciprofloxacin or imipenem use and antimicrobial resistance in Pseudomonas aeruginosa.

METHODS: A retrospective review of monthly antimicrobial susceptibility reports for ciprofloxacin (1988 to 1995) and imipenem (1987 to 1995) against $P$ aeruginosa and hospital antimicrobial use records at a tertiary care teaching hospital in Winnipeg, Manitoba. Data were entered into a relational database, R:Base $4.5++$, collated, transferred to a spreadsheet and subjected to linear regression analysis. The relationship between ciprofloxacin or imipenem use and resistance was assessed using a Pearson correlation.

RESULTS: Ciprofloxacin-resistant $P$ aeruginosa increased from 1.0\% of all isolates in 1988 to $10.0 \%$ in 1995. A significant $(\mathrm{P}=0.05)$ correlation was demonstrated between the amount of ciprofloxacin use and prevalence of ciprofloxacin-resistant $P$ aeruginosa $(\mathrm{r}=0.73, \mathrm{P}=0.05)$. Imipenem-resistant $P$ aeruginosa increased from $1.0 \%$ of isolates in 1987 to a maximum of $10.4 \%$ in 1991 , and subsequently decreased to $5.4 \%$ in 1995 . Imipenem use and the prevalence of imipenem-resistant $P$ aeruginosa were significantly correlated $(r=0.85, \mathrm{P}=0.014)$.

CONCLUSIONS: Ciprofloxacin use was directly associated with ciprofloxacin resistance, and imipenem use was directly associated with imipenem resistance in $P$ aeruginosa.
\end{abstract}

Key Words: Ciprofloxacin, Imipenem, Resistance, Pseudomonas aeruginosa

\section{Corrélation entre ciprofloxacine ou imipénème et résistance de Pseudomonas aeruginosa}

OBJECTIF : Étudier le lien entre le recours à la ciprofloxacine ou à l'imipénème et la résistance de Pseudomonas aeruginosa aux antimicrobiens.

MÉTHODES : Étude rétrospective des rapports mensuels de sensibilité de $P$. aeruginosa aux antimicrobiens ciprofloxacine (1988 à 1995) et imipénème (1987 à 1995) et de l'utilisation des antimicrobiens dans un centre hospitalier universitaire de soins tertiaires de Winnipeg, au Manitoba. Les données ont été consignées dans une base de données relationnelles “ Base R 4,5++ ”, colligées et transférées sur une feuille de calcul, puis soumises à une analyse de régression linéaire. Le lien entre le recours à la ciprofloxacine ou à l'imipénème et la résistance a été évalué à l'aide d'une corrélation de Pearson.

voir page suivante

${ }^{1}$ Departments of Medicine and Medical Microbiology and Faculties of Medicine and Pharmacy, University of Manitoba; ${ }^{2}$ Departments of Medicine, Clinical Microbiology and Pharmaceutical Services, Health Sciences Centre, Winnipeg, Manitoba

Correspondence and reprints: Dr GG Zhanel, MS6-Microbiology, Health Sciences Centre, 820 Sherbrook Street, Winnipeg, Manitoba R3A 1 R9.

Telephone 204-787-4902, fax 204-787-4699, e-mail ggzhanel@pcs.mb.ca

Received for publication November 20, 1997. Accepted March 26, 1998 
RÉSULTATS : Lles souches de $P$. aeruginosa résistantes à la ciprofloxacine ont augmenté de $1 \%$ de tous les isolats en 1988 à de $10 \%$ en 1995. Une corrélation significative $(\mathrm{P}=0,05)$ a été démontrée entre la quantité de ciprofloxacine utilisée et la prévalence des souches de $P$. aeruginosa qui lui sont résistantes $(\mathrm{r}=0,73, \mathrm{P}=0,05)$. Les souches de $P$. aeruginosa résistantes à l'imipénème sont passées de $1 \%$ des isolats en 1987 à un maximum de 10,4\% en 1991, avant de diminuer à 5,4 \% en 1995. L'emploi de l'imipénème et la prévalence des souches de $P$. aeruginosa résistantes à l'imipénème se sont révélés être en corrélation significative $(\mathrm{r}=0,85, \mathrm{P}=0,014)$.

CONCLUSIONS : L'emploi de la ciprofloxacine et l'emploi de l'imipénème ont été directement associés à la résistance de $P$. aeruginosa à leur endroit.

A ntimicrobial resistance is a global problem of increasing concern $(1,2)$. Infection caused by antimicrobialresistant organisms is associated with increased morbidity and mortality, and increased length of hospital stay $(1,2)$. The increasing prevalence of antimicrobial resistance has been associated with a number of factors, including increasing numbers of immunocompromised patients in hospitals, increasing use of invasive clinical procedures, world travel leading to rapid dissemination of antimicrobial-resistant organisms and intense antimicrobial use $(1,2)$.

Although there appears to be a relationship between antimicrobial use and the development of resistance $(3,4)$, not all reports support this correlation (5). In addition, whether the relationship between antimicrobial use and the development of resistance is causal or simply an association is unclear $(3,4)$. This study analyzed the incidence of Pseudomonas aeruginosa resistance to ciprofloxacin and imipenem in a tertiary care medical centre from 1987 to 1995, inclusive, to correlate the change in resistance patterns of this organism with the intensity of ciprofloxacin and imipenem use in the facility.

\section{PATIENTS AND METHODS}

The study was conducted at the Health Sciences Centre Winnipeg, Manitoba from January 1987 to December 1995. The Health Sciences Centre is an 850-bed tertiary care referral institution. It is the main teaching hospital in Manitoba (population 1,200,000), with over 22,000 admission per year. Clinical programs at the Health Sciences Centre include intensive care units (medical, surgical, paediatric and neonatal), a burn unit, major cancer treatment centre, cardiovascular surgery program, transplant program (bone marrow, renal and lung) and cystic fibrosis program.

$P$ aeruginosa (out-patient and in-patient isolates) isolated from all sites, including blood ( $1.5 \%$ of isolates), urine $(20 \%$ of isolates) and other, such as sputum, wound and body fluids (for example, pleural fluid) (78.5\% of isolates) were included. Repeat isolates from the same patient were included if they were identified more than seven days apart. Over the eightyear study period (1987 to 1995), the same commercial microdilution system was used. Autoscan 4 (American Microscan, California), together with Microscan commercially prepared conventional panels were used for antimicrobial susceptibility testing. Minimal inhibitory concentration (MIC) breakpoints for defining susceptibility, intermediate susceptibility and resistance were $1 \mathrm{~g} / \mathrm{mL}$ or less, $2 \mathrm{~g} / \mathrm{mL}$ and $4 \mathrm{~g} / \mathrm{mL}$ or greater for ciprofloxacin, and $4 \mathrm{~g} / \mathrm{mL}$ or less, $8 \mathrm{~g} / \mathrm{mL}$ and $16 \mathrm{~g} / \mathrm{mL}$ or greater for imipenem, respectively (6). Thus, ciprofloxacin- and imipenem-resistant isolates had MICs $4 \mathrm{~g} / \mathrm{mL}$ or greater and $\quad \mathrm{g} / \mathrm{mL}$ or greater, respectively. During the study period, both ciprofloxacin and imipenem were classified as 'restricted' agents requiring Section of Infectious Diseases verbal approval (oral ciprofloxacin) or formal Infectious Diseases consultation (parenteral ciprofloxacin, imipenem).

Data from monthly Microscan reports from 1988 to 1995 (ciprofloxacin) and 1987 to 1995 (imipenem) were reviewed and entered into a relational database (R:Base $4.5++$, Microrim, Washington). Data were collated and exported into the Excel (Microsoft, Washington) spreadsheet program for further analysis. Statistical analysis using linear regression was conducted using the Number Cruncher Statistical System (NCSS, Utah). The relationship between ciprofloxacin and imipenem use, and resistance was assessed using a Pearson correlation. Ciprofloxacin and imipenem use were based on drug purchase data obtained from the pharmacy department.

\section{RESULTS}

Ciprofloxacin: Ciprofloxacin was introduced into the hospital formulary in late 1987. Usage increased from 1988 to 1990 inclusive, as did the prevalence of ciprofloxacin-resistant $P$ aeruginosa (1\% to $7.3 \%$ ) (Figure 1). In 1991, ciprofloxacin use increased; however, the incidence of ciprofloxacinresistant $P$ aeruginosa decreased to $6.7 \%$. From 1992 to 1995 , ciprofloxacin use stabilized at approximately $45 \mathrm{~g} / 1000 \mathrm{pa}-$ tient days. The incidence of ciprofloxacin-resistant $P$ aeruginosa stabilized in 1993 to 1995 at 10\%. Figure 1 illustrates the relationship between ciprofloxacin use and the incidence of ciprofloxacin-resistant $P$ aeruginosa. Ciprofloxacin use significantly correlated with ciprofloxacin-resistant $P$ aeruginosa $(r=0.73, P=0.05)$.

Imipenem: Imipenem was introduced into the hospital formulary in 1987. Imipenem use increased from 1987 to 1989 , as did the incidence of imipenem-resistant $P$ aeruginosa ( $1 \%$ to $10.4 \%$ ) (Figure 2). The use of imipenem stabilized in 1989 and 1990, as did the incidence of imipenem-resistant $P$ aeruginosa (10.4\% and $10.6 \%$, respectively). In 1991, the use of imipenem increased to approximately $11 \mathrm{~g} / 1000$ patient days, as did the incidence of imipenem-resistant $P$ aeruginosa (11.4\%). Use decreased in 1992 and 1993, with a slight increase in 1994 and 1995. $P$ aeruginosa-resistance to imipenem decreased in 1992 to $7.1 \%$ and in 1993 to $4.4 \%$; it increased in 1994 to $5.4 \%$ and in 1995 to $6.0 \%$. Figure 2 illustrates the relationship between imipenem use and the incidence of imipenem-resistant $P$ aeruginosa. Imipenem use significantly correlated with imipenem-resistant $P$ aeruginosa $(\mathrm{r}=0.85, \mathrm{P}=0.014)$. 


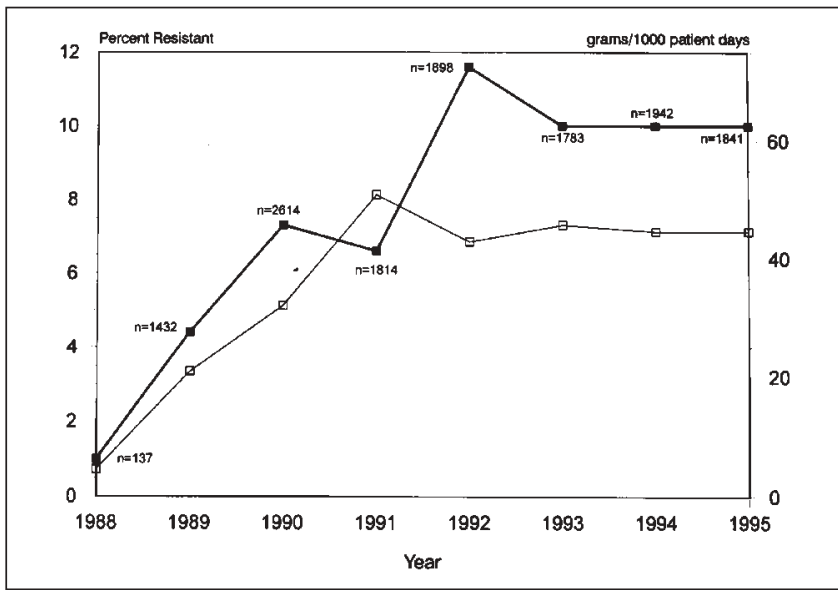

Figure 1) Relationship between ciprofloxacin use (grams per 1000 patient days) and the prevalence of ciprofloxacin-resistant Pseudomonas aeruginosa from 1987 to 1995. The number of isolates tested in each year is shown

\section{DISCUSSION}

$P$ aeruginosa is an important nosocomial pathogen that is characterized by its propensity to develop antimicrobial resistance. Our experience documents a significant correlation between the use of two broad-spectrum antimicrobials, ciprofloxacin and imipenem, and resistance to $P$ aeruginosa. As ciprofloxacin use increased, the prevalence of resistant isolates also increased, while as ciprofloxacin use stabilized or decreased, the development of ciprofloxacin-resistant $P$ aeruginosa stabilized or decreased, respectively (Figure 1). A similar relationship was observed with imipenem. As imipenem use increased, the prevalence of imipenem-resistant $P$ aeruginosa also increased (Figure 2). When imipenem use stabilized or decreased, the development of imipenem-resistant $P$ aeruginosa stabilized or decreased, respectively.

Although results demonstrate a close relationship between ciprofloxacin or imipenem use and the development of ciprofloxacin- or imipenem-resistant $P$ aeruginosa, many variables may affect this relationship (7-10). No significant changes occurred in the number of admissions per year or in the type of patients admitted during the study period (1987 to 1995). Furthermore, to the best of our knowledge, the level of care remained unchanged during this period. There were no substantial changes in infection control practices, infection rates or antimicrobial restriction practices. Criteria used to identify ciprofloxacin- or imipenem-susceptible or resistant $P$ aeruginosa did not change during the study period. Finally, both ciprofloxacin and imipenem were classified as 'restricted' antimicrobials immediately upon acceptance into the hospital formulary, and no change in this restriction policy occurred during the study period.

Limitations included the fact that our observations reflect hospital-wide data that cannot be analyzed within specialty units (for example, burn unit or intensive care unit). Previous data have demonstrated problems with resistant pseudomonas within specialty units that may not be evident from hospital-wide information (8). In addition, assuming that

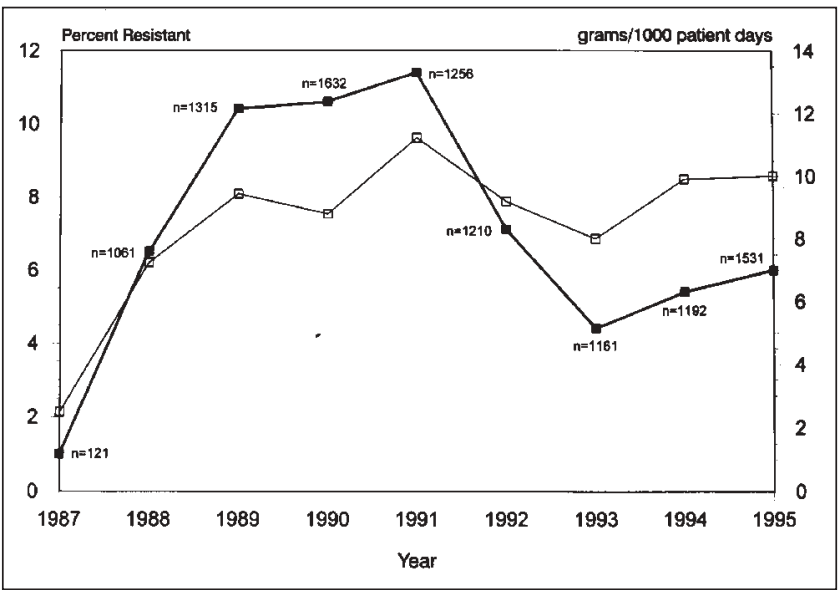

Figure 2) Relationship between imipenem use (grams per 1000 patient days), and the prevalence of imipenem-resistant Pseudomonas aeruginosa from 1987 too 1995. The number of isloates tested in each year is shown

drug purchase data are equivalent with drug use may be misleading (8). This study also did not consider resistance arising due to combination antimicrobial therapy, such as imipenem plus an aminoglycoside (11). The data on ciprofloxacin are also limited because ciprofloxacin may reflect out-patient use in addition to the hospital use, which could not be controlled for. Furthermore, it is possible that resistant isolates could be over-represented if repeated cultures were taken from identical patients at intervals of greater than one week.

Several studies have attempted to correlate antimicrobial use and the development of resistance. Some reports have demonstrated a relationship between antimicrobial use and bacterial resistance $(12,13)$, while others have not confirmed this correlation (5). Studies performed with aminoglycosides have either been prospective studies in which a baseline period was followed by an extensive usage period of one aminoglycoside (7,14-16), usually amikacin, or retrospective studies reporting the frequency of aminoglycoside resistance among clinical isolates over several years $(17,18)$. The majority of these studies have demonstrated a clear relationship between the use of gentamicin, tobramycin and kanamycin, and bacterial resistance $(7,14-16)$. However, with amikacin, several studies have not shown a relationship between amikacin use and amikacin resistance (7,14-16), while other studies have reported increased amikacin resistance with increased amikacin use $(17,18)$.

Whether there is a relationship between beta-lactam use and bacterial resistance is less clear. Ballow and Schentag (8), using data from the National Nosocomial Resistance Surveillance Group, evaluated 18 hospitals in the United States and reported a relationship between ceftazidime use and Enterobacter cloacae resistance to ceftazidime from 1988 to 1990 (8). Within the Health Sciences Centre in Winnipeg, the high frequency of ceftazidime-resistant Enterobacter cloacae was reduced substantially with restriction of ceftazidime use (8). These investigators found no relationship between ceftazidime use and ceftazidime-resistant $P$ aeruginosa (8). This 
lack of a correlation may reflect the consistent use of the drugs with an aminoglycoside. The authors found no relationship between ceftazidime $(\mathrm{P}=0.28)$ or piperacillin $(\mathrm{P}=0.15)$ use and the development of resistant $P$ aeruginosa. Jones (19) reported a relationship between ceftazidime use and ceftazidime-resistant $P$ aeruginosa at the University of Iowa Hospitals and Clinics location from 1986 to 1988. After restricting ceftazidime use, which resulted in approximately $50 \%$ reduction in the drug's use, susceptibility of $P$ aeruginosa to ceftazidime recovered (19). Bamberger and Dahl (20) assessed the impact of voluntary versus enforced compliance with ceftazidime use and the frequency of ceftazidimeresistant $P$ aeruginosa (20). Over a 15 -month period during which time staff were not forced to adhere to institutional guidelines for ceftazidime use, ceftazidime use was high and $P$ aeruginosa resistance to ceftazidime was $73 \%$. During the next six months, medical staff were forced to adhere to established guidelines (compliance with formulary guidelines had to be present in the patient chart). Ceftazidime use decreased during this period, and sensitivity of $P$ aeruginosa to ceftazidime increased to $80 \%$. Courcol and colleagues (21) evaluated antimicrobial susceptibility and usage data from three clinical departments (intensive care unit, respiratory unit and chest surgery) at a French university hospital from 1980 to 1986 (21). Over the study period, investigators demonstrated significant increases in the use of third-generation cephalosporins (greater than 10,000 g/year), especially cefotaxime, and significant increases in the frequency of cefotaximeresistant Escherichia coli (0\% to 12\%), Klebsiella pneumoniae (4\% to $40 \%$ ), E cloacae (30\% to $45 \%$ ), Serratia marcescens (25\% to $45 \%$ ) and $P$ aeruginosa (50\% to $70 \%$ ). Significant increases in the use of aminoglycosides, for example, netilmicin and amikacin, occurred during the study period. Although significant increases in netilmicin-resistant $K$ pneumoniae $(\mathrm{P}=0.03)$ and $E$ cloacae $(\mathrm{P}=0.04)$ occurred, no relationship between amikacin use and resistance was observed. Fass et al (22) reviewed the use of ciprofloxacin and imipenem with susceptibility to $P$ aeruginosa over an eight-year period (1986 to 1993) in an American midwest university teaching hospital. These investigators reported increasing ciprofloxacin resistance (3\% to $16 \%$ ) over the study period, which was associated with increasing ciprofloxacin use $(0$ to greater than 2000 doses/month). Imipenem resistance also increased ( $0 \%$ to $9 \%)$ over the study period, along with increased imipenem use $(0$ to $1000 /$ doses/month). Thus, the majority of data indicate that antimicrobial resistance is associated with antimicrobial use; the greater the use is the greater the development of resistance to that agent. It is unclear why there are conflicting data regarding the relationship between beta-lactam use and antimicrobial resistance.

Whether there is a causal relationship between antimicrobial usage and antimicrobial resistance or simply an association is controversial. Several lines of evidence suggest that the relationship is a causal one. Evidence for a causal relationship include the observation that changes in antimicrobial use are paralleled by changes in the prevalence of antimicrobial resistance, and that antimicrobial resistance is more prevalent in bacterial strains causing nosocomial infection than in organisms from community-acquired infections. In addition, during nosocomial infection outbreaks, patients infected with resistant strains are more likely to have received previous antimicrobial therapy than control patients. Areas within the hospital having the highest use of antimicrobials also have the highest prevalence of antimicrobial resistance, and increasing the dosage or duration of antimicrobial therapy leads to a greater likelihood of colonization with antimicrobial-resistant organisms $(3,4,23,24)$.

\section{CONCLUSIONS}

The evidence presented supports the association of ciprofloxacin and imipenem use with the development of ciprofloxacin-resistant or imipenem-resistant $P$ aeruginosa. In addition, even with restricted and limited antimicrobial use, clinically important levels of resistance occur. Why some antibiotic use relates to resistance and other antibiotic use does not remains an area for future research.

ACKNOWLEDGMENTS: Dr George Zhanel is the holder of the Merck Frosst Chair in Pharmaceutical Microbiology, Winnipeg, Manitoba. The authors thank Mrs Wegrzyn for expert secretarial assistance. Financial support for this research was provided in part by grants from the Manitoba Health Research Council and the Allied Health Research Foundation.

\section{REFERENCES}

1. O'Brien TF. The global epidemic nature of antimicrobial resistance and the need to monitor and manage it locally. Clin Infect Dis 1997;24(Suppl 1):2-8.

2. Acar JF. Consequences of bacterial resistance to antibiotics in medical practice. Clin Infect Dis 1997;24(Suppl 1):S17-8.

3. McGowan JE Jr. Antimicrobial resistance in hospital organisms and its relation to antibiotic use. Rev Infect Dis $1983 ; 5: 1033-48$

4. McGowan JE Jr. Is antimicrobial resistance in hospital microorganisms related to antibiotic use? Bull NY Acad Med 1987;63:253-68.

5. Rollag H, Midtredt T, Hovig B, Dahl O. Sensitivity patterns of bacteria and antibiotic usage at the national hospital of Norway in 1976 and 1978. Zentral Bakteriol Parasiten Infektion Hyg 1979;244:514-24.

6. National Committee for Clinical Laboratory Standards (NCCLS). Methods for dilution antimicrobial susceptibility tests for bacteria that grow aerobically. M7-A2. Villanova: National Committee for Clinical Laboratory Standards, 1991.

7. Betts RF, Valenti WM, Chapman SW, et al. Five-year surveillance of aminoglycoside usage in a university hospital. Ann Intern Med 1984;100:219-22.

8. Ballow $\mathrm{CH}$, Schentag JJ. Trends in antibiotic utilization and bacterial resistance. Report of the National Nosocomial Resistant Surveillance Group. Diagn Microbiol Infect Dis 1992;15(Suppl 2):37S-42S.

9. McGowan JE. Do intensive hospital antibiotic control programs prevent the spread of antibiotic resistance. Infect Cont Hosp Epidemiol 1994;15:478-83.

10. Gaynes R. Surveillance of antibiotic resistance: learning to live with bias. Infect Cont Hosp Epidemiol1995;16:623-6.

11. White RL, Friedrick LV, Mihm LB, Bosso JA. Evaluation of changes in susceptibility (S) of Gram-negative aerobes: pitfalls in examining only single drug relationships. 37 th Interscience Conference on Antimicrobial Agents and Chemotherapy (ICAAC). Toronto, September 29 to October 1, 1997. (Abst C-26) 
12. Jarlier V, Sinegre M, Bismuth R, Nguyen J. [Relationship between bacterial sensitivity to antimicrobial agents and their consumption.] Nouv Presse Med 1981;10:3545-8.

13. Mouton RP, Glerum JH, van Loenen AC. Relationship between antibiotic consumption and frequency of antibiotic resistance of four pathogens - a seven-year survey. J Antimicrob Chemother 1976;2:9-19.

14. Gerding DN, Larson TA. Aminoglycoside resistance in Gram negative bacilli during increased amikacin use. Comparison of experience in 14 United States hospitals with experience in the Minneapolis Veterans Administration Medical Centre. Am J Med 1985;19(Suppl 1A):1-7.

15. Berk SL, Alvarez S, Ortega G, Verghese A, Holtclaw-Berk SA. Clinical and microbiologic consequences of amikacin use during a 42-month period. Arch Intern Med 1986;146:538-41.

16. Gerding DN, Larson TA, Hughes RA, Weiler M, Shanholtzer C, Peterson LR. Aminoglycoside resistance and aminoglycoside usage: ten years of experience in one hospital. Antimicrob Agents Chemother 1991;35:1284-90.

17. Levine JF, Maslow MJ, Leibowitz RE, et al. Amikacin-resistant Gram-negative bacilli: Correlation of occurrence with amikacin use. J Infect Dis 1976;2:9-19.
18. Wormser GP, Tatz J, Donath J. Endemic resistance to amikacin among hospital isolates of Gram-negative bacilli: implications for therapy. Infect Cont 1983;4:93-9.

19. Jones RN. The current and future impact of antimicrobial resistance among nosocomial bacterial pathogens. Diagn Microbiol Infect Dis 1992;15(Suppl 2):3S-10S.

20. Bamberger DM, Dahl SL. Impact of voluntary vs enforced compliance of third-generation cephalosporin use in a teaching hospital. Arch Intern Med 1992;152:554-7.

21. Courcol RJ, Pinkas M, Martin GR. A seven year survey of antibiotic susceptibility and its relationship with usage. J Antimicrob Chemother 1989;23:441-51.

22. Fass RJ, Barnishan J, Ayers LW. Emergence of bacterial resistance to imipenem and ciprofloxacin in a university hospital. J Antimicrob Chemother 1995;36:343-53.

23. Embil JM, Kabani A, Zhanel G, Nicolle LE. Low prevalence of gastrointestinal colonization with antimicrobial-resistant bacteria in high risk units in a Canadian tertiary care centre. Can J Infect Dis 1996; 7:307-12.

24. John JF Jr, Fishman NO. Programmatic role of the infectious diseases physician in controlling antimicrobial costs in the hospital. Clin Infect Dis 1997;24:471-85. 


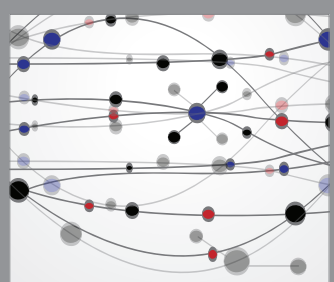

The Scientific World Journal
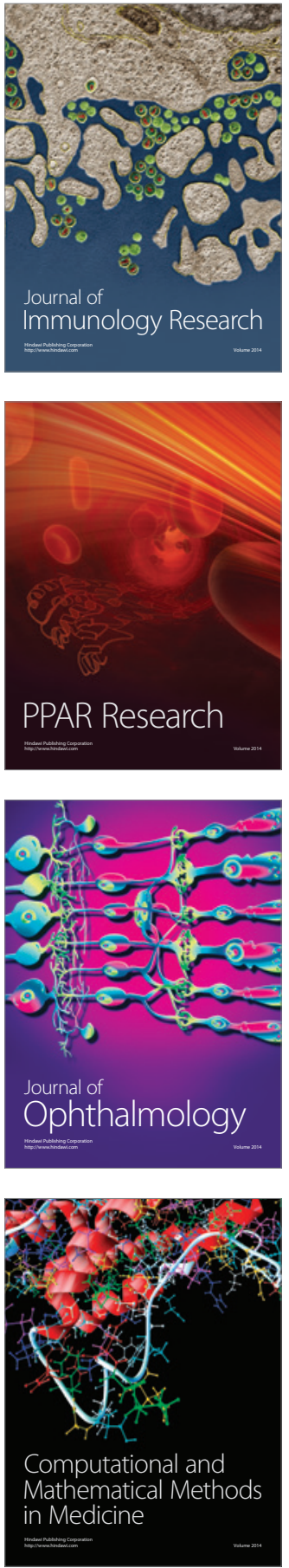

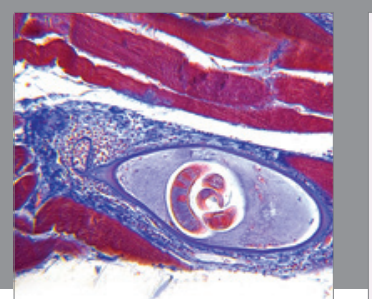

Gastroenterology Research and Practice

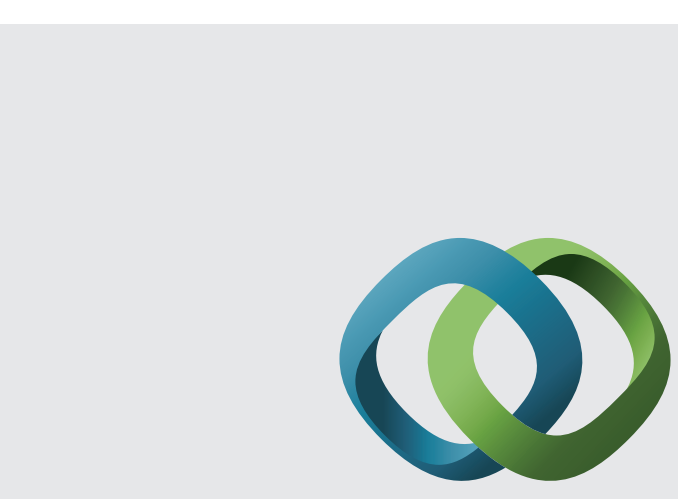

\section{Hindawi}

Submit your manuscripts at

http://www.hindawi.com
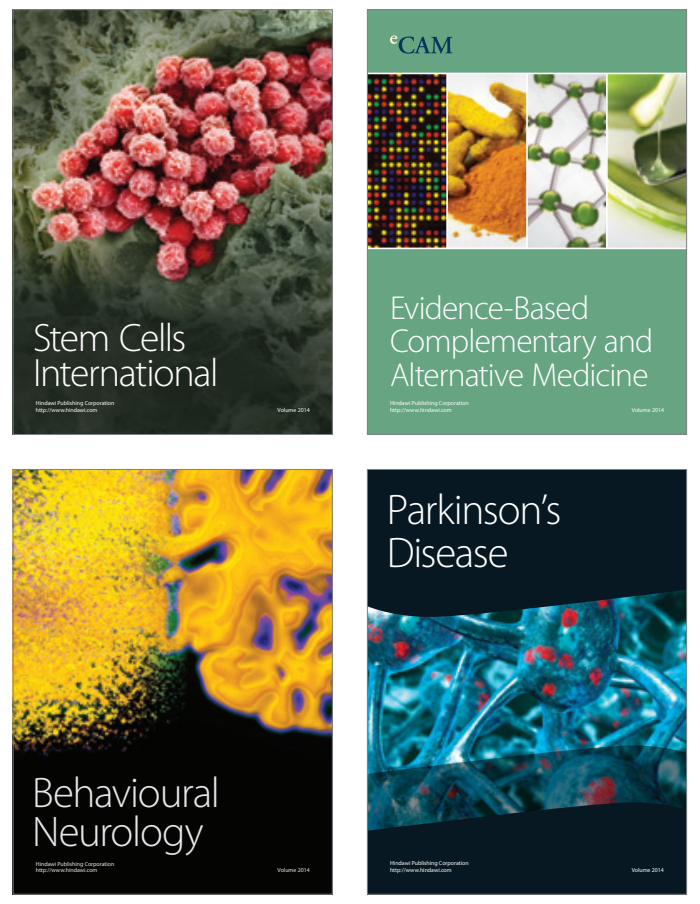
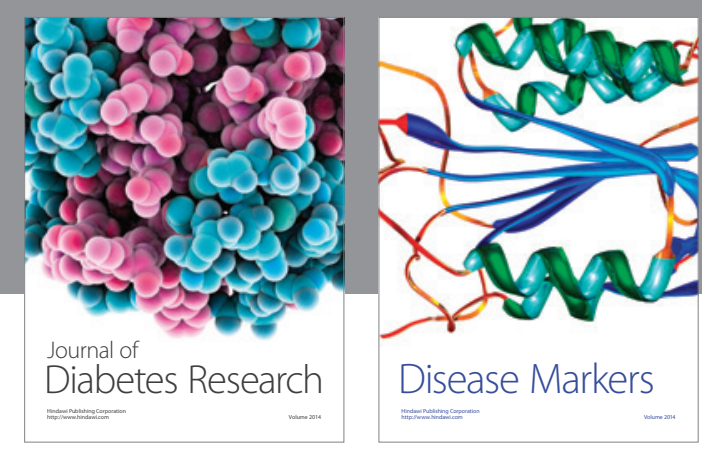

Disease Markers
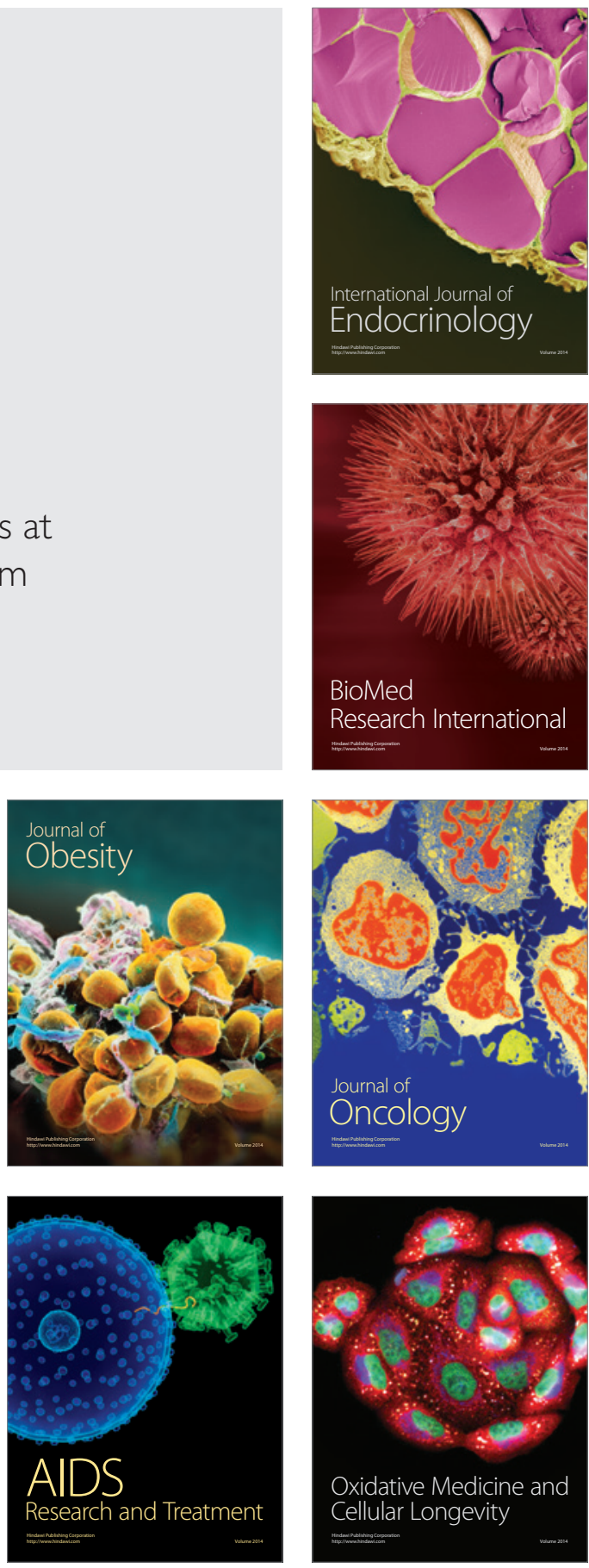